\title{
A positron emission tomography imaging study to confirm target engagement in the lungs of patients with idiopathic pulmonary fibrosis following a single dose of a novel inhaled av $\beta 6$ integrin inhibitor
}

Toby M. Maher ${ }^{1,2}$, Juliet K. Simpson ${ }^{3}$, Joanna C. Porter ${ }^{4}$, Frederick J. Wilson ${ }^{3}$, Robert Chan ${ }^{3}$, Rhena Eames ${ }^{3}$, Yi Cui ${ }^{3}$, Sarah Siederer ${ }^{3}$, Simon Parry ${ }^{3}$, Julia Kenny ${ }^{3}$, Robert J. Slack ${ }^{3}$, Jagdeep Sahota ${ }^{4}$, Lyn Paul $^{1}$, Peter Saunders ${ }^{1,2}$, Philip L. Molyneaux ${ }^{1,2}$, Pauline T. Lukey ${ }^{3}$, Gaia Rizzo ${ }^{5}$, Graham E. Searle ${ }^{5}$, Richard P. Marshall ${ }^{3}$, Azeem Saleem ${ }^{5}$, Arthur R. Kang'ombe ${ }^{3}$, David Fairman ${ }^{3}$, William A. Fahy ${ }^{3}$ and Mitra Vahdati-Bolouri ${ }^{3^{*}}$

\begin{abstract}
Background: Idiopathic pulmonary fibrosis (IPF) is a chronic, progressive lung disease with poor prognosis and a significant unmet medical need. This study evaluated the safety, pharmacokinetics (PK) and target engagement in the lungs, of GSK3008348, a novel inhaled alpha-v beta-6 (avß6) integrin inhibitor, in participants with IPF.

Methods: This was a phase 1b, randomised, double-blind (sponsor unblind) study, conducted in the UK (two clinical sites, one imaging unit) between June 2017 and July 2018 (NCT03069989). Participants with a definite or probable diagnosis of IPF received a single nebulised dose of 1000 mcg GSK3008348 or placebo (ratio 5:2) in two dosing periods. In period 1, safety and PK assessments were performed up to $24 \mathrm{~h}$ post-dose; in period 2, after a 7day to 28-day washout, participants underwent a total of three positron emission tomography (PET) scans: baseline, Day 1 ( 30 min post-dosing) and Day 2 ( $24 \mathrm{~h}$ post-dosing), using a radiolabelled av $\beta 6$-specific ligand, $\left[{ }^{18} \mathrm{~F}\right] \mathrm{FB}-$ A20FMDV2. The primary endpoint was whole lung volume of distribution $\left(V_{T}\right)$, not corrected for air volume, at $\sim 30$ min post-dose compared with pre-dose. The study success criterion, determined using Bayesian analysis, was a posterior probability (true $\%$ reduction in $V_{T}>0 \%$ ) of $\geq 80 \%$.

Results: Eight participants with IPF were enrolled and seven completed the study. Adjusted posterior median reduction in uncorrected $V_{T}$ at $~ 30$ min after GSK3008348 inhalation was 20\% (95\% Crl: -9 to 42\%). The posterior probability that the true $\%$ reduction in $V_{T}>0 \%$ was $93 \%$. GSK3008348 was well tolerated with no reports of serious adverse events or clinically significant abnormalities that were attributable to study treatment. PK was successfully characterised showing rapid absorption followed by a multiphasic elimination.

(Continued on next page)
\end{abstract}

* Correspondence: mitra.x.vahdati-bolouri@gsk.com

${ }^{3}$ GlaxoSmithKline Research and Development, Stevenage, UK

Full list of author information is available at the end of the article

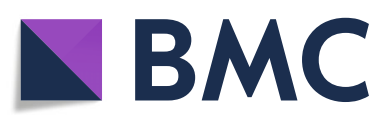

( ) The Author(s). 2020 Open Access This article is licensed under a Creative Commons Attribution 4.0 International License, which permits use, sharing, adaptation, distribution and reproduction in any medium or format, as long as you give appropriate credit to the original author(s) and the source, provide a link to the Creative Commons licence, and indicate if changes were made. The images or other third party material in this article are included in the article's Creative Commons licence, unless indicated otherwise in a credit line to the material. If material is not included in the article's Creative Commons licence and your intended use is not permitted by statutory regulation or exceeds the permitted use, you will need to obtain permission directly from the copyright holder. To view a copy of this licence, visit http://creativecommons.org/licenses/by/4.0/ The Creative Commons Public Domain Dedication waiver (http://creativecommons.org/publicdomain/zero/1.0/) applies to the data made available in this article, unless otherwise stated in a credit line to the data. 
(Continued from previous page)

Conclusions: This study demonstrated engagement of the av $\beta 6$ integrin target in the lung following nebulised dosing with GSK3008348 to participants with IPF. To the best of our knowledge this is the first time a target-specific PET radioligand has been used to assess target engagement in the lung, not least for an inhaled drug.

Trial registration: clinicaltrials.gov: NCT03069989; date of registration: 3 March 2017.

Keywords: Alpha-v beta-6, avß6, Integrin, Idiopathic pulmonary fibrosis, IPF, positron emission tomography, PET, $\left[{ }^{18} \mathrm{~F}\right] \mathrm{FB}-\mathrm{A} 20 \mathrm{FMDV} 2$, target engagement

\section{Background}

Idiopathic pulmonary fibrosis (IPF) is a specific form of chronic, progressive interstitial pneumonia of unknown cause $[1,2]$. It occurs primarily in adults and the clinical course varies amongst diagnosed individuals from slow progression to acute decompensation and death, with a median survival time in untreated patients of just 2 to 4 years $[1,2]$. Pharmacological treatment is currently limited to two oral anti-fibrotics, pirfenidone and nintedanib, both of which have been shown to reduce the rate of decline in lung function but are associated with significant side effects [2]. There remains a considerable unmet need for new therapies to treat this disease.

The alpha-v beta- $6(\alpha v \beta 6)$ integrin has a major role in the activation of transforming growth factor- $\beta$ (TGF $\beta$ ), a cytokine that is central to the development of IPF [3]. The expression of $\alpha v \beta 6$ is upregulated in IPF lung tissue [4], and increased levels of $\alpha v \beta 6$ are associated with disease progression and poor prognosis [5], suggesting that an inhibitor of $\alpha v \beta 6$ may provide therapeutic benefits to patients with IPF. GSK3008348 is a novel, small molecule $\alpha v \beta 6$ integrin inhibitor that has been developed for inhaled delivery via nebulisation and is the first inhaled compound in this class [6]. In vitro, GSK3008348 demonstrates selective and high affinity binding to the $\alpha v \beta 6$ integrin, inducing fast internalisation and degradation of the integrin. In an in vivo mouse model of lung fibrosis, inhaled GSK3008348 inhibited the activation of TGF $\beta$ [7]. GSK 3008348 has previously been demonstrated to be well tolerated at single doses up to $3000 \mathrm{mcg}$ in healthy human participants, with a pharmacokinetic (PK) profile that was dose proportional at potentially clinically relevant doses [8].

Positron emission tomography (PET) imaging using the $\alpha v \beta 6$-selective $\left[{ }^{18} \mathrm{~F}\right] \mathrm{FB}$-A20FMDV2 PET ligand provides a non-invasive method for measuring $\alpha v \beta 6$ expression and a potential model for assessing target engagement of inhaled therapies in the lung $[9,10]$. In a study of 15 participants (6 healthy, 9 with pulmonary fibrosis), lung uptake of $\left[{ }^{18} \mathrm{~F}\right] \mathrm{FB}-$ A20FMDV2 measured by lung volume of distribution $\left(\mathrm{V}_{\mathrm{T}}\right)$, a partition co-efficient that acts as a marker of expression of the integrin $\alpha v \beta 6$, was successfully quantified. This demonstrated increased expression in IPF compared with healthy participants [10]. Additionally, $\left[{ }^{18} \mathrm{~F}\right] \mathrm{FB}-\mathrm{A} 20 \mathrm{FMDV} 2$ was well-tolerated and the PET measures were reproducible over a two-week period. An independent study has recently reported similar results with an alternative av $\beta 6$-specific PET ligand $\left(\left[{ }^{18} \mathrm{~F}\right] \mathrm{FP}-\mathrm{R}_{0} 1-\mathrm{MG}-\mathrm{F} 2\right)$ [11].

The aim of this study was to evaluate the safety, tolerability and PK of GSK3008348 in participants with IPF and to obtain preliminary information on target engagement using the $\left[{ }^{18} \mathrm{~F}\right] \mathrm{FB}-\mathrm{A} 20 \mathrm{FMDV} 2$ PET ligand.

\section{Methods \\ Study design}

This phase $1 \mathrm{~b}$ study was conducted at three centres in the UK (two clinical sites [Royal Brompton Hospital and University College London Hospital, London, UK] and one imaging unit [Invicro, London, UK]) between June 2017 and July 2018. The study was designed to comprise up to two cohorts (cohort 2 was optional) (Study 204,715, NCT03069989). In cohort 1, under double-blind (sponsor unblind) conditions, participants were randomised 5:2 to receive a single nebulised dose of either $1000 \mathrm{mcg}$ GSK3008348 or placebo in two dosing periods (Fig. 1).

Dosing period 1 was to assess safety and PK; participants remained in the clinical unit overnight to enable regular safety and PK assessments up to $24 \mathrm{~h}$ post-dose. Dosing period 2 was to enable assessment of target engagement. After a wash out period of 7 to 28 days following the first dose, participants attended the imaging unit on an outpatient basis for a pre-dose PET scan (pre-dose PET), to determine baseline levels of pulmonary uptake of the $\alpha v \beta 6$-specific tracer, as well as a highresolution computed tomography (HRCT) scan. Following the baseline scan, participants attended the clinical unit for safety assessments and once deemed fit to continue, attended the imaging unit for their second dose of study medication and post-dose PET scans: Day $1[\sim 30$ min post-dosing (PET 1)] and Day 2 [ 24 h post-dosing (PET 2)]. There was a maximum of 14 days between the baseline PET scan and the PET scan on Day 1.

Optional cohort 2 was to enable further exploration of the safety of GSK3008348 and/or target engagement if required. Following completion of cohort 1 , no safety signals emerged that warranted further investigation and the pre-defined study success criterion for GSK3008348 target engagement was met. This, together with the 


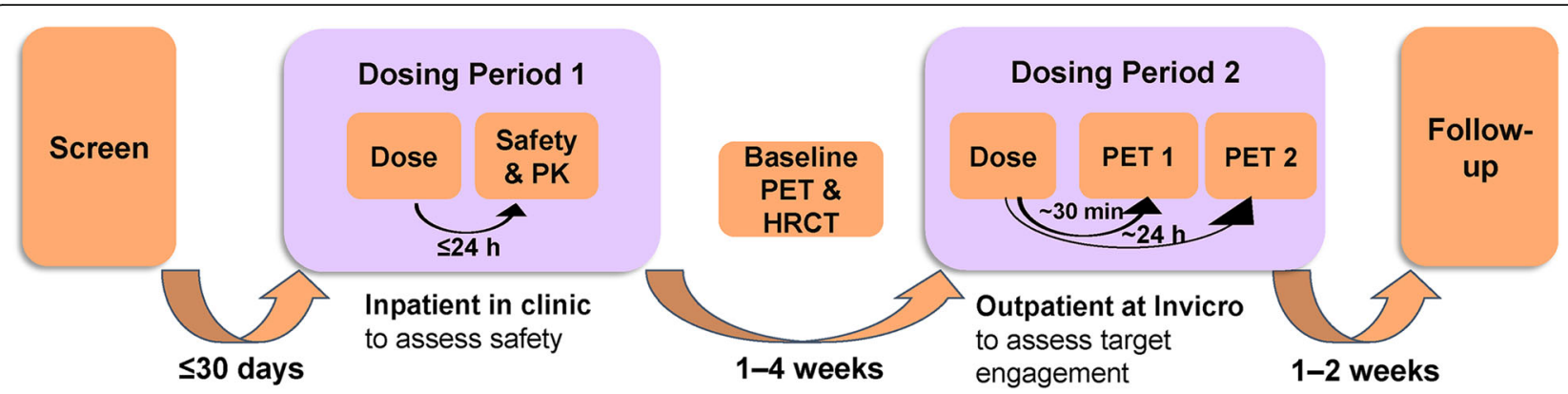

Fig. 1 Study schematic for cohort 1. HRCT: high-resolution computed tomography; PET: positron emission tomography; PK: pharmacokinetics; PET1: PET scan on day 1 at $\sim 30$ min post-dose; PET2: PET scan on day 2 at $\sim 24 \mathrm{~h}$ post-dose

operational complexities of the study, led to the decision to stop the study prior to progression to cohort 2.

To ensure consistency of nebulised dosing the same model of Philips Sidestream Plus nebuliser (Philips, Guildford, United Kingdom) was used at each site. The 1000 mcg dose was selected for two reasons;

1) It was lower than the maximum $3000 \mathrm{mcg}$ dose used in healthy volunteers, which would enable significant safety margins in the event that systemic exposure was higher in IPF patients than healthy volunteers.

2) PK from the study in healthy participants [10], demonstrated peak systemic unbound concentrations at $1000 \mathrm{mcg}$ that were significantly in excess of the in vitro dissociation constant $(\mathrm{Kd})$. As lung tissue exposures are likely to be at least as high as the systemic exposure, it was expected that $\alpha v \beta 6$ would demonstrate significant engagement at this dose.

The study was approved by the National Research Ethics Service Committee London and the Administration of Radioactive Substances Advisory Committee of the UK. Written informed consent was obtained from all participants.

\section{Participants}

Eligible participants were male (aged $\geq 50$ years) or female (aged $\geq 55$ years) with a definite or probable diagnosis of IPF [12], forced vital capacity (FVC) $>50 \%$ predicted and diffusing capacity of the lungs for carbon monoxide (DLCO) $>40 \%$ predicted. Body weight was required to be $\geq 45 \mathrm{~kg}$ and body mass index within the range of 18.5 to $35.0 \mathrm{~kg} / \mathrm{m}^{2}$. Participants who were currently taking pirfenidone or nintedanib (or who had received either within 30 days of the first dose of study treatment), had a current IPF exacerbation or respiratory tract infection, a post-bronchodilator forced expiratory volume in $1 \mathrm{~s}\left(\mathrm{FEV}_{1}\right) / \mathrm{FVC}$ ratio $<0.70$, or known hepatic or biliary abnormalities were excluded. Full details of the eligibility criteria can be found on ClinicalTrials.gov (https://clinicaltrials.gov/ct2/show/NCT0306 9989).

\section{PET imaging assessments}

Dynamic $\left[{ }^{18} \mathrm{~F}\right] \mathrm{FB}-\mathrm{A} 20 \mathrm{FMDV} 2 \mathrm{PET}$ scans were acquired using a Siemens PET/CT system Biograph 6 TruePoint with TrueV or a Hi-Rez Biograph 6 (Siemens Healthcare, Erlangen, Germany). Full details of the methodology for image acquisition and analysis have been detailed elsewhere [10]. In brief, for each PET scan, $\left[{ }^{18} \mathrm{~F}\right] \mathrm{FB}-\mathrm{A} 20 \mathrm{FMDV} 2$ was injected into a cubital or forearm vein through an intravenous cannula and emission data were acquired for up to $90 \mathrm{~min}$. An additional venous cannula was used to collect blood samples throughout the PET scan for quantification of the total and unmetabolized $\left[{ }^{18} \mathrm{~F}\right] \mathrm{FB}$-A20FMDV2-related radioactivity in whole blood and plasma. These data were used alongside the images to derive an input function for the analysis of emission PET data based on a volume of interest (VOI) in the descending aorta. Using time activity curves from the whole lung VOI, PET outcome parameters of dynamic $\mathrm{V}_{\mathrm{T}}$, a partition coefficient derived using a kinetic model, and static standardised uptake value (SUV), integrated from 10 to 30 mins post tracer administration, were obtained. Both $V_{T}$ and SUV measures were expressed with and without correction for air volume referred to as air-corrected $\mathrm{V}_{\mathrm{T}}$ and SUV and uncorrected $V_{T}$ and SUV from here on.

The primary pharmacodynamic endpoint was the change in the uptake of $\left[{ }^{18} \mathrm{~F}\right] \mathrm{FB}-\mathrm{A} 20 \mathrm{FMDV} 2$ in the whole lung, assessed as uncorrected $\mathrm{V}_{\mathrm{T}}$ at $\sim 30 \mathrm{~min}$ post-dose compared with pre-dose. $\mathrm{V}_{\mathrm{T}}$ was chosen a priori as the appropriate measure to assess uptake of the $\alpha v \beta 6$ PET ligand as it intrinsically accounts within the kinetic model for any distributional changes in the ligand, for example altered blood kinetics, that may be caused by the effects of a therapeutic $\alpha v \beta 6$ inhibitor. 
The total maximum effective radiation dose received per participant was estimated to be $20.9 \mathrm{mSv}$ [13], comprised of three PET scans each with up to two low-dose computed tomography scans for attenuation correction, and a HRCT scan which was performed once only at baseline in dosing period 2 for anatomical localisation.

\section{Safety assessments}

Full safety assessments were conducted at screening, pre-dose baseline and at regular intervals during each dosing period, including vital signs (blood pressure, heart rate, respiratory rate and temperature), 12-lead electrocardiograms (ECGs), routine safety laboratory tests and lung function. Oxygen saturation was measured continuously from pre-dose to $4 \mathrm{~h}$ post-dose in dosing period 1. Adverse events (AEs) were monitored throughout the study.

\section{Pharmacokinetic assessments}

PK blood samples $(2 \mathrm{~mL})$ were collected at pre-dose, and at 15 and $30 \mathrm{~min}, 1,2,4,8,12,18$ and $24 \mathrm{~h}$ post-dose in dosing period 1, and on Day 1 (pre-dose, 15 and $30 \mathrm{~min}$, 2 and $4 \mathrm{~h}$ post-dose) and Day 2 (on arrival and discharge at the imaging unit) in dosing period 2. Plasma samples were analysed for GSK3008348 using a validated analytical method based on protein precipitation extraction followed by liquid chromatography tandem mass spectrometry (LC-MS/MS) (Covance, Harrogate, UK). The lower limit of quantification for GSK3008348 was $50 \mathrm{pg} /$ $\mathrm{mL}$ using a $50-\mu \mathrm{L}$ aliquot of human plasma with an upper limit of quantification of $50,000 \mathrm{pg} / \mathrm{mL}$.

\section{Statistical methods}

A required sample size of five participants in the GSK3008348 group was based on a within-subject standard deviation in uncorrected $\mathrm{V}_{\mathrm{T}}$ between two PET scans of 0.15 and a minimum detectable reduction of $6.2 \%$ [10]. The primary endpoint, change in uncorrected $V_{T}$ at $~ 30$ min post-dose compared with pre-dose, was analysed using a Bayesian repeated measures model assuming non-informative priors of the form $\mathrm{N}$ (mean $=0$, $\mathrm{SD}=1000$ ) for all model parameters and a Toeplitz covariance matrix. The analysis was based on the PET data from the five participants who received GSK3008348. Placebo participants were included primarily as a comparator for safety assessments. PET data from the placebo participants were included on plots for reference but were not included in the analysis. The adjusted posterior median value of $\mathrm{V}_{\mathrm{T}}$ ratio (PET 1/ Pre-dose PET) was calculated together with corresponding standard deviation and $95 \%$ highest posterior density (HPD) credible interval $(\mathrm{CrI})$. The posterior probability that the true ratio PET1/Pre-dose is less than 1 (= true \% reduction in $\mathrm{V}_{\mathrm{T}}$ at $\sim 30 \mathrm{~min}$ compared to Pre-dose $>0 \%$ ) was calculated and the pre-defined study success criterion was defined as a posterior probability $\geq 80 \%$. The same Bayesian model was used for the analysis of all other PET derived endpoints.

Safety data were summarised descriptively. GSK3008348 plasma concentration-time data were analysed using standard non-compartmental analysis (WinNonlin Version 7.0). Key parameters derived were: area under the concentrationtime curve from time zero to $t$, where $t$ is the time of the last quantifiable concentration $\left(\mathrm{AUC}_{0_{-\mathrm{t}}}\right)$, maximum plasma concentration $\left(\mathrm{C}_{\max }\right)$ and time to $\mathrm{C}_{\max }\left(\mathrm{T}_{\max }\right)$.

\section{Results}

\section{Participant characteristics}

A total of eight participants were randomised, five to GSK3008348 and three to placebo; seven completed the study with a PET scan at $\sim 30$ min post dose (PET 1 ). Four participants ( 3 active, 1 placebo) underwent the $24 \mathrm{~h}$ post dose scan (PET 2). One participant in the placebo group was withdrawn due to PET equipment failures as the post dose PET scans could not be rescheduled within the limits of the protocol. The majority of participants were male ( 7 of 8 ) with a mean age of 70 and 74 years in the placebo and GSK3008348 groups, respectively (Table 1 ). Median (range) percent predicted FVC was relatively well preserved in both groups (Placebo: 93\% (78-94\%); GSK300348: 91\% (79$113 \%)$ ) whilst median (range) DLCO was reduced (Placebo: 43\% (43-50\%); GSK300348: 48\% (42-54\%)).

\section{PET imaging results}

After single nebulised dosing with GSK3008348, adjusted median uncorrected $\mathrm{V}_{\mathrm{T}}$ at $\sim 30 \mathrm{~min}$ post-dose decreased from $1.50 \mathrm{~mL} / \mathrm{cm}^{3}$ to $1.20 \mathrm{~mL} / \mathrm{cm}^{3}$ and a reduction in uncorrected $\mathrm{V}_{\mathrm{T}}$ was observed in all participants in the GSK3008348 group (Fig. 2; Additional File 1, Table S1). The adjusted posterior median reduction was $20 \%(95 \%$ HPD CrI: -9 to $42 \%$ ) and the posterior probability that the true $\%$ reduction at $\sim 30$ min post-dose compared with pre-dose $>0 \%$, was $93 \%$, meeting the pre-defined study success criterion (Table 2). The estimated standard deviation of $\log$ (PET1/Pre-dose) was 0.16 (Table 2). Three of the five participants receiving GSK3008348 had a PET scan at the $\sim 24 \mathrm{~h}$ timepoint (PET 2) and for all three, uncorrected $\mathrm{V}_{\mathrm{T}}$ increased from the $\sim 30 \mathrm{~min}$ post-dose levels (Fig. 2) with a median adjusted $\mathrm{V}_{\mathrm{T}}$ of $1.72 \mathrm{~mL} / \mathrm{cm}^{3}$ at this time point (Additional File 1, Table S1). The estimated adjusted posterior median ratio of PET2/pre-dose was 1.154 (95\% HPD CrI: 0.791, 1.647) and the posterior probability that the true $\%$ reduction at $\sim 24 \mathrm{~h}$ post-dose compared with pre-dose $>0 \%$, was $18 \%$ (Table 2 ).

Data for air-corrected $V_{T}$ showed a similar pattern to uncorrected $\mathrm{V}_{\mathrm{T}}$ with a decrease in signal between PET1 and pre-dose (Additional File 2, Figure S1). However, 
Table 1 Demographic and baseline characteristics

\begin{tabular}{lll}
\hline & $\begin{array}{l}\text { Placebo } \\
(\boldsymbol{N}=3)\end{array}$ & $\begin{array}{l}\text { GSK3008348 1000 mcg } \\
(\boldsymbol{N}=5)\end{array}$ \\
\hline Age (years), mean (SD) & $70.3(3.1)$ & $73.6(2.3)$ \\
Males, $n(\%)$ & $3(100)$ & $4(80)$ \\
BMI (kg/m²), mean (SD) & $31.4(1.1)$ & $27.9(1.9)$ \\
Race, $n$ (\%) & & $5(100)$ \\
White/Caucasian/European heritage & $3(100)$ & \\
Lung function & & $91.0(78.5-113.4)$ \\
FVC percent predicted (\%), median (range) & $92.6(77.9-93.6)$ & $99.0(71.4-123.9)$ \\
FEV percent predicted (\%), median (range) & $90.0(89.8-99.2)$ & $48.0(41.7-53.5)$ \\
DLCO percent predicted (\%), median (range) & $43.3(43.0-50.1)$ & \\
\hline
\end{tabular}

$B M I$ body mass index

the results for SUV (air-corrected and uncorrected) showed a different pattern to the $\mathrm{V}_{\mathrm{T}}$ and did not show a decrease in signal between PET 1 and pre-dose (Additional File 3, Figure S2a and Figure S2b).

\section{Safety results}

Six AEs were reported across four participants, three in the GSK3008348 group and one in the placebo group (Table 3). All AEs were mild in intensity and none were considered treatment related. There were no SAEs reported and no participant withdrawals from the study as a result of safety findings. Furthermore, no clinically significant abnormalities that were attributable to study treatment were reported for clinical laboratory evaluations, ECGs, vital signs or lung function assessments.

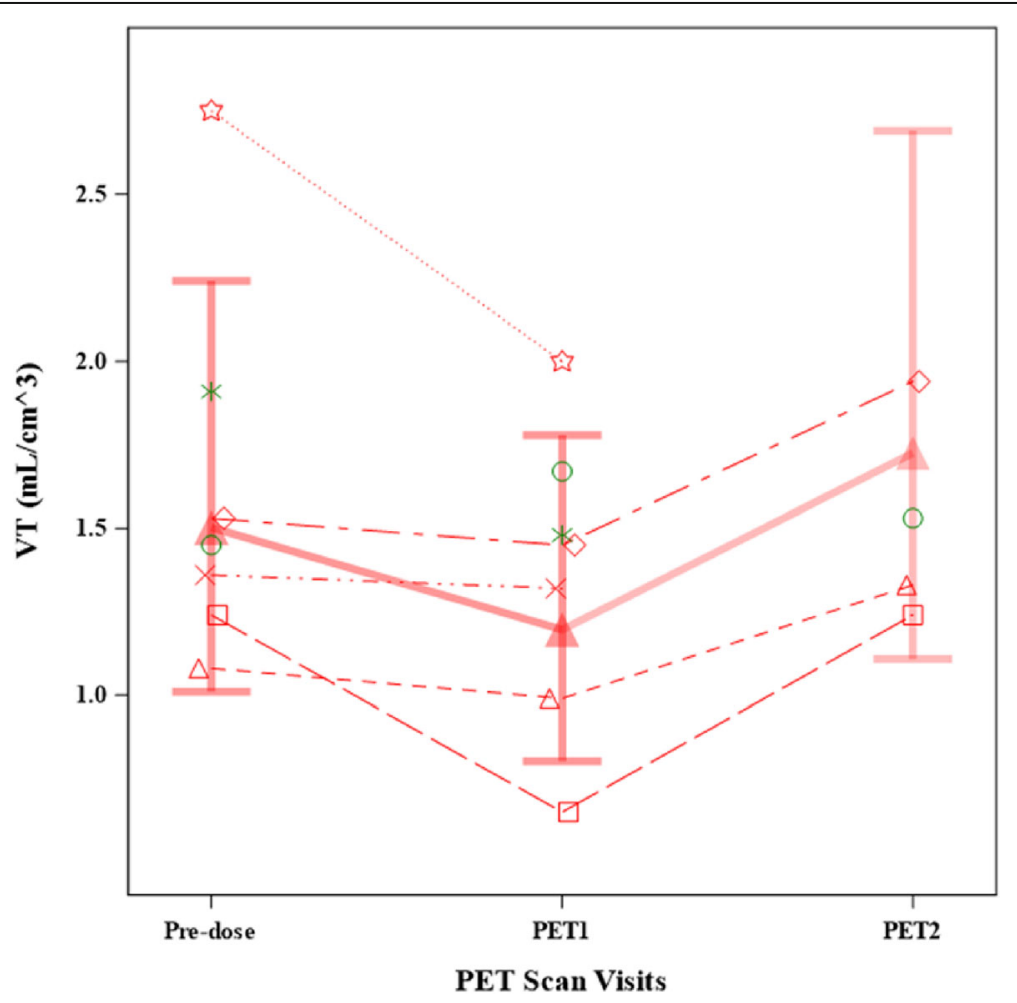

Fig. 2 Summary of adjusted medians of uncorrected $V T$, ( $\mathrm{mL} / \mathrm{cm} 3)$ of [18F]FBA20FMDV2 and individual patient profiles. PET1: PET scan on day 1 at 30 min post-dose; PET2: PET scan on day 2 at $\sim 24 \mathrm{~h}$ post-dose. The adjusted medians (with $95 \% \mathrm{Cr}$ l) were calculated from a Bayesian repeated measures model using data from participants on the GSK3008348 $1000 \mathrm{mcg}$ arm only and is indicated by a thicker line and filled triangles. Data for individual participants dosed with GSK300834 are shown with dotted lines linking the data. Individual subject data is shown for participants on GSK3008348 1000 mcg (red symbols) and placebo (green symbols). The PET data from the placebo participants are included on plots for reference, but were not included in the analysis. 
Table 2 Adjusted posterior median ratios of uncorrected $\mathrm{V}_{\mathrm{T}}\left(\mathrm{mL} / \mathrm{cm}^{3}\right)$

\begin{tabular}{lllll}
\hline Parameter & Adjusted Median of Ratio & 95\% HPD Crl of Ratio & SD Logs of Ratio & Probability $($ True Ratio $<1.0)$ \\
\hline PET1/Pre-dose & 0.797 & $(0.578,1.087)$ & 0.1576 & 0.934 \\
PET2/Pre-dose & 1.154 & $(0.791,1.647)$ & 0.1779 & 0.175 \\
PET2/PET1 & 1.446 & $(0.984,2.083)$ & 0.1868 & 0.030
\end{tabular}

HPD Crl Highest posterior density credible interval; PET positron emission tomography; PET1 PET scan on day 1 at $\sim 30$ min post-dose ( $n=5$ ); PET2 PET scan on day 2 at $\sim 24$ h post-dose $(n=3)$

PET data from the placebo participants were included on plots for reference but were not included in the analysis

\section{Pharmacokinetic results}

The plasma concentration-time profiles indicated rapid absorption of GSK3008348 (median $\mathrm{T}_{\max }$ of $0.5 \mathrm{~h}$ ) followed by a rapid decline in plasma concentrations up to $4 \mathrm{~h}$ post-dose and a slower decline thereafter (Fig. 3, Table 4). Plasma concentrations were measurable up to $24 \mathrm{~h}$ post-dose in period 1 and $30 \mathrm{~h}$ post-dose in period 2 with the exception of two participants whose last sampling time was $22 \mathrm{~h}$. Systemic exposure to GSK3008348, as measured by geometric mean $\mathrm{AUC}_{0-\mathrm{t}}$ and $\mathrm{C}_{\max }$ did not appear markedly different between Dosing periods 1 and 2 . Between subject variability $(\% \mathrm{CVb})$ in total systemic exposure $\left(\mathrm{AUC}_{0-\mathrm{t}}\right.$ and $\mathrm{C}_{\max }$ ) to $\mathrm{GSK} 3008348$ was moderate (range 31 to $58 \%$ ).

\section{Discussion}

This was the first study to evaluate the effects of the inhaled $\alpha v \beta 6$ integrin inhibitor, GSK3008348, in an IPF population not currently treated with pirfenidone or nintedanib. The participants in this study were typical of an IPF population, $80 \%$ male and with a mean age $>70$ years. The majority of participants had preserved FVC (median \% predicted >90\%) but significantly impaired DLCO (median \% predicted of $43.3 \%$ in the placebo group and $48 \%$ in the active treatment group) demonstrating the impact of fibrosis on gas transfer. A single nebulised $1000 \mathrm{mcg}$ dose of GSK3008348 inhibited the uptake of the specific PET ligand $\left[{ }^{18} \mathrm{~F}\right] \mathrm{FB}-\mathrm{A} 20 \mathrm{FMDV} 2$ in the lung at $\sim 30 \mathrm{~min}$ post-dose, providing evidence of target engagement with the $\alpha v \beta 6$ integrin receptor, but not at $\sim 24 \mathrm{~h}$, indicating that the duration of target engagement was less than $24 \mathrm{~h}$, consistent with a priori PK/PD modelling. Single doses of $1000 \mathrm{mcg}$ of

Table 3 Summary of all adverse events by treatment group

\begin{tabular}{lll}
\hline & $\begin{array}{l}\text { Placebo } \\
(\boldsymbol{N}=3)\end{array}$ & $\begin{array}{l}\text { GSK3008348 } \\
1000 \mathrm{mcg} \\
(\mathbf{N}=5)\end{array}$ \\
\hline Number of participants with any AE, $\mathrm{n}(\%)$ & $1(33)$ & $3(60)$ \\
Diarrhoea & $1(33)$ & 0 \\
Urinary tract infection & 0 & $1(20)$ \\
Headache & 0 & $1(20)$ \\
Contact dermatitis & 0 & $1(20)$ \\
Tooth extraction & 0 & $1(20)$ \\
\hline
\end{tabular}

GSK3008348 were well tolerated, and PK was generally consistent with that observed for healthy volunteers [8].

All participants dosed with GSK3008348 showed a reduction in uncorrected $\mathrm{V}_{\mathrm{T}}$, the primary endpoint, thus supporting the robustness of this finding. It is recognised that the treatment response differed between participants. It is difficult to explain the reasons for this in such a small study, but possible explanations include differences in drug exposure in the lungs and disease severity or activity. The variability (SD) of the data in the active group was 0.16 , comparing favourably with the value of 0.15 assumed in the sample size calculations during study design, which were based on the test-retest variability measured in a previous enabling study, where PET scans were repeated $\sim 12$ days apart in patients with IPF [10].

The rationale for selecting uncorrected $V_{T}$ as the primary endpoint was well considered when designing this study. IPF is characterized by interstitial pneumonia together with fibrosis and the distribution of air, fibrosis and blood in the lung varies according to the stage of fibrosis, all important factors to consider when interpreting lung $\left[{ }^{18} \mathrm{~F}\right] \mathrm{FB}-\mathrm{A} 20 \mathrm{FMDV} 2$ uptake [14]. $\mathrm{V}_{\mathrm{T}}$ was chosen as the appropriate measure to assess the uptake of the $\alpha v \beta 6$ PET ligand as, unlike SUV, it accounts for any distributional changes in the ligand that may be caused by a therapeutic $\alpha v \beta 6$ inhibitor. This selection was corroborated as SUV indeed showed a different pattern to the $\mathrm{V}_{\mathrm{T}}$ and did not decrease between PET 1 and pre-dose, strongly suggesting that distributional changes were relevant as expected.

The decision to use uncorrected rather than aircorrected $V_{\mathrm{T}}$ as the primary endpoint was based on the assumption that the fraction of air in the lung would be unchanged for an individual participant in this shortduration study. The relative changes in the post-dose air-corrected $V_{T}$ were similar to those for uncorrected $\mathrm{V}_{\mathrm{T}}$, justifying this assumption. As the reduction from pre-dose to $\sim 30$-min post-dose air-corrected $V_{\mathrm{T}}$ also met the pre-defined success criterion, this further supported the primary endpoint results.

The data presented here are insufficient alone to allow interpretation of how the $20 \%$ reduction in uncorrected $\mathrm{V}_{\mathrm{T}}$ relates to the level of target engagement. However, putting these results into context, it is comparable to the $17 \%$ difference seen between IPF and healthy participants 


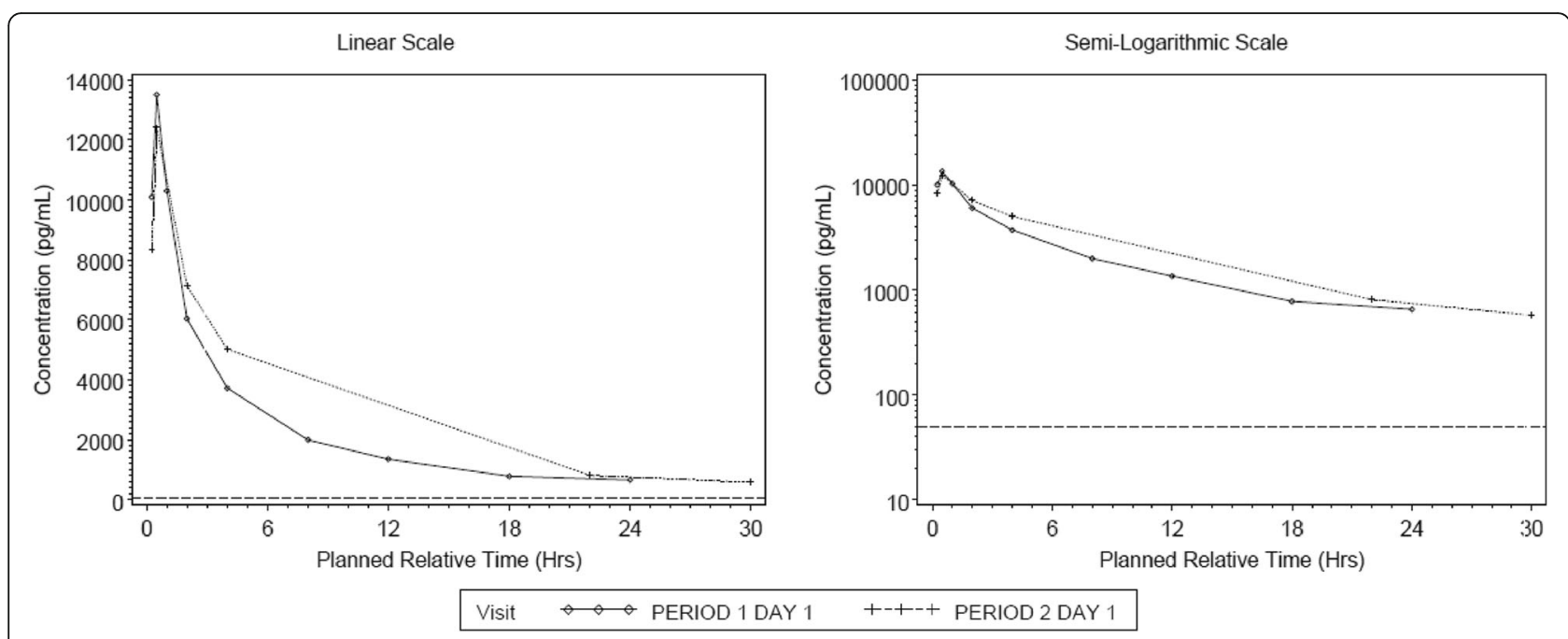

Fig. 3 Median plasma GSK3008348 concentration-time plot

in air-corrected $V_{T}$ [10], suggesting that it is a meaningful change. In making this comparison it is important to consider that some of the difference in PET signal between IPF and healthy participants will be due to reduced air fraction in IPF lungs, hence the difference in air-corrected $\mathrm{V}_{\mathrm{T}}$ (which is smaller than the difference in uncorrected $\mathrm{V}_{\mathrm{T}}$ ) is the appropriate comparator. In any case, the consistency in the relative change of uncorrected and aircorrected $\mathrm{V}_{\mathrm{T}}$ values in the current study add further credence to the robustness of the result.

Data on uncorrected $\mathrm{V}_{\mathrm{T}}$ at $\sim 24 \mathrm{~h}$ post-dose, available for three out of five participants receiving GSK3008348, returned to approximate baseline levels - in line with a priori modelling that indicated the duration of action would be less than $24 \mathrm{~h}$ and hence not supporting a once daily dosing regimen for this drug. However, further study would be required to characterise the drug's duration of action fully.

In this preliminary study in IPF patients, inhaled GSK3008348 was well tolerated with no AEs or clinically relevant findings attributable to treatment. The PK profile following single inhaled dosing demonstrated rapid absorption and multi-phasic elimination of GSK3008348. Furthermore, there was significant overlap in systemic exposure $\left(\mathrm{C}_{\max }\right.$ and AUC) to GSK3008348 in IPF patients compared with healthy participants following a $1000 \mathrm{mcg}$ single dose [8].

\section{Conclusion}

This first-time in patient IPF study successfully demonstrated that a nebulised $1000 \mathrm{mcg}$ dose of GSK3008348 inhibited the uptake in the lung of a target-specific PET ligand for the $\alpha v \beta 6$ integrin at $30 \mathrm{~min}$ but not at $\sim 24 \mathrm{~h}$ post-dose, providing evidence of target engagement and indicating a duration of target engagement of less than $24 \mathrm{~h}$. Further study would be required to confirm the level of target engagement and to assess its impact on downstream pharmacology. GSK3008348 was well tolerated and PK was consistent with the PK profile shown in healthy subjects. To the best of our knowledge, this is the first time that a target-specific radioligand has been used to assess target engagement of a putative

Table 4 Summary of Derived Plasma GSK3008348 Pharmacokinetic Parameters

\begin{tabular}{|c|c|c|c|c|c|}
\hline PK Parameter (units) & $\mathrm{N}$ & Period & Geometric Mean & $95 \% \mathrm{Cl}$ & $\% \mathrm{CVb}$ \\
\hline \multirow{2}{*}{$\begin{array}{l}\text { AUC(0-t) } \\
\left(h^{*} p g / m L\right)\end{array}$} & 5 & Period 1 & 64,638 & $(33,065,126,362)$ & 58 \\
\hline & 5 & Period 2 & 66,123 & $(39,036,112,005)$ & 44 \\
\hline \multirow{2}{*}{$\begin{array}{l}C_{\max } \\
(\mathrm{pg} / \mathrm{mL})\end{array}$} & 5 & Period 1 & 14,050 & $(8876,22,243)$ & 38 \\
\hline & 5 & Period 2 & 10,418 & $(7191,15,094)$ & 31 \\
\hline \multirow{2}{*}{$\begin{array}{l}T_{\max }{ }^{1} \\
\text { (h) }\end{array}$} & 5 & Period 1 & 0.50 & $(0.4-0.5)$ & \\
\hline & 5 & Period 2 & 0.47 & $(0.4-0.5)$ & \\
\hline
\end{tabular}

$A \cup C_{0-t}$ area under the concentration-time curve from time zero to time of last quantifiable concentration; $C_{\text {max }}$ maximum plasma concentration; $T_{\text {max }}$ time to maximum plasma concentration

${ }^{1} \mathrm{~T}_{\max }$ expressed as median (range) 
therapeutic compound in the lung, demonstrating proof of principle that PET imaging can enhance the understanding of pharmacology in early pulmonary drug development.

\section{Supplementary information}

Supplementary information accompanies this paper at https://doi.org/10. 1186/s12931-020-01339-7.

Additional file 1: Uncorrected Volume of Distribution VT; Table S1. Adjusted posterior median uncorrected VT $\left(\mathrm{mL} / \mathrm{cm}^{3}\right)$.

Additional file 2: Air-corrected $V_{T}$; Figure S1. Summary of adjusted medians of air-corrected $V_{T},\left(\mathrm{~mL} / \mathrm{cm}^{3}\right)$ of $\left.{ }^{18} \mathrm{~F}\right]$ FB-A2OFMDV2 and individual patient profiles

Additional file 3: Uncorrected and air-corrected Standardised Uptake Values (SUV); Figure S2a. Summary of adjusted medians of uncorrected SUV $(\mathrm{g} / \mathrm{mL})$ of $\left[{ }^{18} \mathrm{~F}\right] \mathrm{FB}-A 20 \mathrm{FMDV} 2$ and individual patient profiles; Figure S2b. Summary of adjusted medians of air-corrected SUV $(\mathrm{g} / \mathrm{mL})$ of $\left[{ }^{18} \mathrm{~F}\right]$ FB-A20FMDV2 and individual patient profiles

\section{Abbreviations}

AE: Adverse event; avß6: Alpha-v beta-6; $\mathrm{AUC}_{0-\mathrm{t}}$ : Area under the concentration-time curve from time zero to time of last quantifiable concentration; BMl: Body mass index; Crl: Credible interval; $C_{\max }$ : Maximum plasma concentration; CVb: Between subject coefficient of variation; DLCO: Diffusing capacity of the lungs for carbon monoxide; ECG: Electrocardiogram; $\mathrm{FEV}_{1}$ : Forced expiratory volume in $1 \mathrm{~s}$; FVC: Forced vital capacity; HRCT: Highresolution computed tomography; HPD: Highest posterior density: IPF: Idiopathic pulmonary fibrosis; Kd: Dissociation constant; LC-MS/ MS: Liquid chromatography tandem mass spectrometry; PET: Positron emission tomography; PET1: Positron emission tomography scan on Day 1, $\sim 30$ min post-dosing; PET2: Positron emission tomography scan on Day 2, $24 \mathrm{~h}$ post-dosing; PK: Pharmacokinetics; SUV: Standard uptake value; TGF $\beta$ : Transforming growth factor- $\beta ; T_{\max }$ : Time to maximum plasma concentration; VOI: Volume of interest; $\mathrm{V}_{\mathrm{T}}$ : Volume of distribution

\section{Acknowledgements}

Editorial support was provided by Kate Hollingworth of Continuous Improvement Ltd. and funded by GSK.

\section{Authors' contributions}

Substantial contributions to study concept and design: TMM, JCP, JS, JKS, RC, RE, YC, SP, JK, RJS, FJW, PTL, RPM, ARK, DF, WAF, MVB. Data acquisition: TMM, JCC, JS, PLM, PS, LP, GR, GES, AS. Data analysis and interpretation: GR, GES, AS, $J K S, R C, R E, Y C, S S, S P, R J S, F J W, A R K, W A F, M V B$. All authors have revised the work critically for important intellectual content and have provided final approval of the version to be published. Authors give their agreement to be accountable for all aspects of the work in ensuring that questions related to the accuracy or integrity of any part of the work are appropriately investigated and resolved. The author(s) read and approved the final manuscript.

\section{Funding}

This study was funded by GlaxoSmithKline (GSK; study number 204715, NCT03069989) and was facilitated by the NOCRI Respiratory Translational Research Partnership. Part of this work was undertaken at UCLH/UCL BRC and Clinical Research Facility who received a proportion of funding from the Department of Health's NIHR Biomedical Research Centres funding scheme.

\section{Availability of data and materials}

Anonymized individual participant data and study documents can be requested for further research from: https://www.clinicalstudydatarequest.com

\section{Ethics approval and consent to participate}

The study was approved by the London - Central Research Ethics Committee, UK (reference 17/LO/0284; IRAS: 221453), Medicine and Healthcare Products Regulatory Agency (MHRA; EudraCT number: 2016003674-41) and permission to administer radioisotopes was obtained from the Administration of Radioactive Substances Advisory Committee of the UK
(Ref: 630/3925/36090). Written informed consent was obtained from all participants prior to participation.

\section{Consent for publication \\ Not applicable.}

\section{Competing interests}

TMM has received consultancy fees and, via his institution, has received research funding from GlaxoSmithKline (GSK). JCP received funding from GSK for a clinical fellow but received no personal fees and has no other disclosures. PLM via his institution has received industry-academic funding from AstraZeneca and has received speaker and consultancy fees from Boehringer Ingelheim and Hoffman-La Roche which fall outside the submitted work. GR, GES and AS are employees of Invicro; and GES and AS are former employees of GSK. JKS, FJW, RC, RE, YC, SS, SP, JK, DF, WAH and MVB are employees of and shareholders in GSK. PTL is a former employee of and owns shares in GSK and is now an independent consultant (Target to Treatment Consulting Ltd). RJS, RPM and ARK are former employees of and current shareholders in GSK. JS, LP and PS declare they have no competing interests.

\section{Author details}

${ }^{1}$ Royal Brompton Hospital, London, UK. ${ }^{2}$ National Heart and Lung Institute, Imperial College London, London, UK. ${ }^{3}$ GlaxoSmithKline Research and Development, Stevenage, UK. ${ }^{4}$ University College London Hospital, London, UK. ${ }^{5}$ Invicro, A Konica Minolta Company, London, UK.

Received: 23 December 2019 Accepted: 18 March 2020 Published online: 26 March 2020

\section{References}

1. Thomson CC, Duggal A, Bice T, Lederer DJ, Wilson KC, Raghu G. 2018 clinical practice guideline summary for clinicians: diagnosis of idiopathic pulmonary fibrosis. Ann Am Thorac Soc. 2019;16:285-90.

2. Raghu G. Pharmacotherapy for idiopathic pulmonary fibrosis: current landscape and future potential. Eur Respir Rev. 2017;26:170071.

3. Goodwin A, Jenkins G. Role of integrin-mediated TGF $\beta$ activation in the pathogenesis of pulmonary fibrosis. Biochem Soc Trans. 2009;37:849-54

4. Slack RJ, Fisher AJ, Denyer JC, Flint DJ, Pyne S. Quantification of av $\beta 6$ integrin expression in normal and fibrotic human lung tissue. Proc Brit Pharmacol Soc. 2015;13(1):P022.

5. Saini G, Porte J, Weinreb PH, Violette SM, Wallace WA, McKeever TM, Jenkins G. avß6 integrin may be a potential prognostic biomarker in interstitial lung disease. Eur Respir J. 2015;46:486-94.

6. Procopiou PA, Anderson NA, Barrett J, Barrett TN, Crawford MHJ, Fallon $B J$, et al. Discovery of ( S)-3-(3-(3,5-Dimethyl-1 H-pyrazol-1-yl)phenyl)-4-(( R)3-(2-(5,6,7,8-tetrahydro-1,8-naphthyridin-2-yl)ethyl)pyrrolidin-1-yl) butanoic acid, a Nonpeptidic av $\beta 6$ integrin inhibitor for the inhaled treatment of idiopathic pulmonary fibrosis. J Med Chem. 2018;61:8417-43.

7. Slack R, John A, Forty E, Mercer P, Graves R, Pun T, et al. Discovery of a novel, high affinity, small molecule av $\beta 6$ inhibitor for the treatment of idiopathic pulmonary fibrosis. QJM. 2016;109(Suppl 1):S60.

8. Maden CH, Fairman D, Chalker M, Costa MJ, Fahy WA, Garman N, et al. Safety, tolerability and pharmacokinetics of GSK3008348, a novel integrin avß6 inhibitor, in healthy participants. Eur J Clin Pharmacol. 2018;74:701-9.

9. Hausner SH, DiCara D, Marik J, Marshall JF, Sutcliffe JL. Use of a peptide derived from foot-and-mouth disease virus for the noninvasive imaging of human cancer: generation and evaluation of $4-\left[{ }^{18} \mathrm{~F}\right]$ fluorobenzoyl A20FMDV2 for in vivo imaging of integrin alphavbeta6 expression with positron emission tomography. Cancer Res. 2007;67:7833-40.

10. Lukey PT, Coello C, Gunn R, Parker C, Wilson FJ, Saleem A, et al. Clinical quantification of the integrin avB6 by [18F]FB-A20FMDV2 positron emission tomography in healthy and fibrotic human lung (PETAL Study). Eur J Nucl Med Mol Imaging. 2020;47:967-79.

11. Kimura RH, Wang L, Shen B, Huo L, Tummers W, Filipp FV, et al. Evaluation of integrin av $\beta 6$ cystine knot PET tracers to detect cancer and idiopathic pulmonary fibrosis. Nat Commun. 2019;10(1):4673.

12. Raghu G, Collard HR, Egan JJ, Martinez FJ, Behr J, Brown KK, et al, on behalf of the ATS/ERS/JRS/ALAT Committee on Idiopathic Pulmonary Fibrosis. An official ATS/ERS/JRS/ALAT statement: Idiopathic pulmonary fibrosis: Evidence-based guidelines for diagnosis and management. Am J Respir Crit Care Med. 2011;183:788-24. 
13. Keat N, Kenny J, Chen K, Onega M, Garman N, Slack RJ, et al. A microdose PET study of the safety, immunogenicity, biodistribution, and radiation dosimetry of 18F-FB-A2OFMDV2 for imaging the integrin avß6. J Nucl Med Technol. 2018;46:136-43.

14. Chen DL, Cheriyan J, Chilvers ER, Choudhury G, Coello C, Connell M, et al.

Quantification of lung PET images: Challenges and opportunities. J Nucl Med. 2017; 58:201-7.

\section{Publisher's Note}

Springer Nature remains neutral with regard to jurisdictional claims in published maps and institutional affiliations.

Ready to submit your research? Choose BMC and benefit from:

- fast, convenient online submission

- thorough peer review by experienced researchers in your field

- rapid publication on acceptance

- support for research data, including large and complex data types

- gold Open Access which fosters wider collaboration and increased citations

- maximum visibility for your research: over $100 \mathrm{M}$ website views per year

At BMC, research is always in progress.

Learn more biomedcentral.com/submissions 